\title{
PENGARUH MODEL KOOPERATIF TIPE TALKING STICK DISERTAI METODE EKSPERIMEN TERHADAP HASIL BELAJAR FISIKA PADA PESERTA DIDIK KELAS XI SMA NEGERI 5 PALU
}

\author{
Dewi Purnama Sari, Yusuf Kendek, dan Syamsu
}

\author{
Jurusan Pendidikan MIPA \\ Fakultas Keguruan dan IImu Pendidikan Universitas Tadulako Palu
}

\begin{abstract}
Abstrak-Penelitian ini bertujuan untuk mengetahui ada tidaknya pengaruh model pembelajaran kooperatif tipe talking stick disertai metode eksperimen terhadap hasil belajar fisika pada peserta didik kelas XI SMA Negeri 5 Palu. Jenis penelitian ini merupakan eksperimen kuasi dengan desain posttestonly control group design. Teknik sampling yang digunakan dalam penelitian ini adalah proposive sampling dengan sampel penelitian adalah kelas XI MIPA 4 sebagai kelompok eksperimen $(n=29)$ dan kelas XI MIPA 3 sebagai kelompok kontrol $(n=30)$. Pada kelas eksperimen diberi perlakuan dengan menggunakkan model pembelajaran kooperatif tipe Talking Stick dan kelas kontrol menggunakan model pembelajaran Direct Instruction, dimana kedua kelas menggunakan metode eksperimen. Setelah pembelajaran selesai, kedua kelas diberikan tes akhir untuk menguji hasilnya. Berdasarkan hasil dari kedua kelas, dari analisa data diperoleh bahwa skor rata-rata kelompok eksperimen 14,81 dan skor ratarata kelompok kontrol yaitu 9,03. Berdasarkan hasil uji hipotesis, diperoleh $t_{\text {hitung }}=6,255$ dan $t_{0,05(44)}=$ 2,00247 pada taraf nyata $a=0,05$. Hal ini menunjukan bahwa terdapat pengaruh model pembelajaran kooperatif tipe taling stick disertai metode eksperimen terhadap hasil belajar fisika pada peserta didik kelas XI SMA Negeri 5 Palu.
\end{abstract}

Kata Kunci: talking stick, hasil belajar fisika.

\section{PENDAHULUAN}

Salah satu masalah dalam dunia pendidikan yaitu rendahnya hasil belajar peserta didik. Oleh karena itu peran aktif pengajar khususnya guru harus lebih memperhatikan faktor-faktor yang mempengaruhi hasil belajar sedemikian rupa hingga dapat terjadi proses belajar yang optimal. Dominasi guru dalam proses pembelajaran menyebabkan kecenderungan peserta didik lebih bersifat pasif sehingga mereka lebih banyak menunggu sajian guru dari pada mencari dan menemukan sendiri pengetahuan [1].

Salah satu cara yang dapat digunakan guru untuk mencapai hasil belajar peserta didik secara optimal yaitu dengan memilih dan menggunakan model pembelajaran yang tepat dan sesuai sehingga dapat tercipta suasana kegiatan belajar mengajar yang baik. Salah satu alternatif untuk mengatasi permasalahan di atas adalah penggunaan model pembelajaran kooperatif. Pembelajaran kooperatif (cooperative learning) merupakan bentuk pembelajaran dengan cara peserta didik belajar dan bekerja dalam kelompok-kelompok kecil secara kolaboratif yang anggotanya terdiri empat sampai enam orang dengan struktur kelompok yang bersifat heterogen. Salah satu model pembelajaran yang inovatif adalah model pembelajaran kooperatif tipe talking stick [2].

Model pembelajaran talking stick termasuk salah satu model pembelajaran kooperatif. Model pembelajaran ini dilakukan dengan bantuan tongkat. Siapa yang memegang tongkat wajib menjawab pertanyaan dari guru setelah peserta didik mempelajari materi pokoknya. Selain untuk melatih berbicara, pembelajaran ini akan menciptakan suasana yang menyenangkan dan membuat peserta didik aktif [3].

Model pembelajaran kooperatif tipe Talking Stick ini juga memberikan pengalaman belajar yang menyenangkan, meningkatkan motivasi, kepercayaan diri, yang mana pendekatan tersebut ditujukan untuk memunculkan emosional dan sikap positif dalam proses belajar mengajar yang berdampak pada kecerdasan otak peserta didik [4].

Metode eksperimen digunakan dalam kegiatan proses pembelajaran, peserta didik melakukan sendiri percobaan, mampu mencari dan menemukan sendiri konsep. Metode eksperimen juga dapat membuat peserta didik terlatih berpikir ilmiah yaitu ada masalah, merumuskan masalah, hipotesis, melakukan pengujian dan menarik kesimpulan. Pelaksanaan proses pembelajaran tersebut peserta didik aktif berperan di dalamnya dengan harapan peserta didik mengalami sendiri secara langsung apa yang dipelajari, sehingga dapat meningkatkan prestasi belajar. Dengan demikian, peserta didik dituntut untuk mengalami sendiri, mencari kebenaran, atau mencoba mencari suatu hukum atau dalil, dan menarik kesimpulan atas proses yang dialaminya itu [5].

Hasil penelitian yang dilakukan Fidmatan [6] menyatakan bahwa dengan menerapkan model pembelajaran koperatif tipe Talking Stick dapat meningkatkan minat belajar biologi peserta didik. Hasil penelitian Gintoe [7] dalam penelitiannya menyatakan bahwa berdasarkan hasil penelitian di kelas VIII sebagai kelas eksperimen dengan menggunakan model pembelajaran kooperatif tipe 
Talking Stick lebih baik dan memberikan semangat belajar bagi peserta didik

Adapun tujuan dalam penelitian ini adalah untuk mengetahui ada tidaknya pengaruh model pembelajaran kooperatif tipe Talking Stick disertai metode eksperimen terhadap hasil belajar fisika peserta didik kelas XI SMA Negeri 5 Palu.

Adapun manfaat yang diharapkan dari penelitian ini adalah sebagai berikut :

- Aspek teoritis, diharapkan penelitian ini mampu meningkatkan hasil belajar fisika melalui model pembelajaran kooperatif tipe Talking Stick disertai metode eksprimen.

- Aspek praktis, diharapkan dimasa mendatang penelitian ini menjadi referensi sehingga dapat dikembangkan suatu strategi pembelajaran yang dapat meningkatkan hasil belajar fisika

Hipotesis penelitian ini adalah :

$\mathrm{H}_{0}$ : Tidak ada perbedaan hasil belajar antara yang menggunakan model pembelajaran kooperatif tipe Talking Stick dengan model pembelajaran Direct Instruction.

$\mathrm{H}_{1}$ : Ada perbedaan Tidak ada perbedaan hasil belajar antara yang menggunakan model pembelajaran kooperatif tipe Talking Stick dengan model pembelajaran Direct Instruction.

\section{METODE PENELITIAN}

Jenis penelitian yang digunakan adalah jenis penelitian kuantitatif dengan menggunakan metode eksperimen semu (quasi-experiment).

Desain penelitian yang digunakan yaitu posttest-only control group design. Rancangan ini menggunakan kelas-kelas yang sudah ada sebagai kelompoknya, dengan memilih kelaskelas yang diperkirakan sama keadaan/kondisinya, dalam hal ini sama berdasarkan tingkat kecerdasan.

TABEL 1 NON EQUIVALEN PRETEST-POSTEST DESIGN

\begin{tabular}{ccc}
\hline Kelompok & Perlakuan $(\mathrm{X})$ & Tes Akhir \\
\hline A (Eksperimen) & $\mathrm{X}$ & $\mathrm{O}_{2}$ \\
B (Kontrol) & - & $\mathrm{O}_{2}$ \\
\hline
\end{tabular}

\section{Keterangan:}

A : Kelompokeksperimen

B : Kelompok control

$\mathrm{O}_{2}$ : Test Akhir (posttest)

$\mathrm{X}$ : perlakuan untuk kelompok eksperimen dengan menerapkan model pembelajaran kooperatif tipe talking stick disertai metode eksperiman.

Penelitian ini dilaksanakan di SMAN 5 Palu. Penelitian ini dilakukan pada kelas XI di semester genap tahun pelajaran 2017/2018 selama kurang lebih 4 minggu.

Populasi pada penelitian ini yaitu seluruh peserta didik kelas XI SMAN 5 Palu. Sampel yang digunakan yaitu kelas XI MIPA 4 untuk kelas eksperimen dan kelas XI MIPA 3 untuk kelas kontrol. Pengambilan sampel dilakukan dengan teknik purposive sampling, yaitu teknik pengambilan sampel dengan pertimbangan tertentu, seperti melihat nilai rata-rata peserta didik.

Instrumen yang digunakan dalam penelitian ini yaitu tes. Instrumen tes tertulis berupa soal pilihan ganda. Tes disusun berdasarkan indikator yang disesuaikan dengan kurikulum. Skor yang digunakan pada pilihan ganda adalah bernilai satu (1) untuk jawaban yang benar dan nol (0) untuk jawaban yang salah.

Data yang diperoleh dari penelitian ini selanjutnya diolah dengan menggunakan uji statistik berupa uji normalitas (Chi-kuadrat) [8], uji homogenitas [9], dan uji hipotesis (uji t-dua pihak) [10].

\section{HASIL DAN PEMBAHASAN}

\section{Hasil Penelitian}

1. Hasil Penelitian Skor Tes Hasil Belajar

TABEL 2 DESKRIPSI SKOR TES HASIL BELAJAR PESERTA DIDIK UNTUK KELAS

EKSPERIMEN DAN KELAS KONTROL

\begin{tabular}{ccc}
\hline \multirow{2}{*}{ Uraian } & \multicolumn{3}{c}{ Tes Akhir (Posttest) } \\
\cline { 2 - 3 } & Kelas Eksperimen (XI MIPA 4) & Kelas Kontrol (XI MIPA 3) \\
\hline $\begin{array}{c}\text { Sampel } \\
\text { Skor }\end{array}$ & 29 & 30 \\
\hline $\begin{array}{c}\text { Terendah } \\
\text { Skor }\end{array}$ & 9 & 3 \\
\hline $\begin{array}{c}\text { Tertinggi } \\
\text { Skor }\end{array}$ & 19 & 14 \\
\hline
\end{tabular}




\begin{tabular}{ccc}
\hline Rata-rata & 14,81 & 9,03 \\
\hline Standar Deviasi & 3,10 & 3,19 \\
\hline
\end{tabular}

2. Hasil Uji Normalitas

Uji normalitas data digunakan untuk menggetahui apakah populasi data berdistribusi normal atau tidak. Data yang akan diujikan adalah data hasil Postest pada kelas eksperimen dan kelas kontrol. Pengujian normalitas data Postest pada penelitian ini menggunakan uji Chi-kuadrat dengan kriteria penerimaan $\chi_{\text {hitung }}^{2}<\chi_{\text {tabel }}^{2}$, taraf signifikan $a=0,05$, dan derajat kebebasan $\mathrm{dk}=$ $\mathrm{k}-3$.

TABEL 3 HASIL UJI NORMALITAS DISTRIBUSI TES AKHIR PADA KELAS EKSPERIMEN DAN KELAS KONTROL

\begin{tabular}{ccccc}
\hline No. & Kelas & Nilai $\chi_{\text {hitung }}^{2}$ & Nilai $\chi_{\text {tabel }}^{2}$ & Keputusan \\
\hline 1. & Eksperimen & 2,67 & 7,81 & Terdistribusi Normal \\
\hline 2. & Kontrol & 4,93 & 7,81 & Terdistribusi Normal \\
\hline
\end{tabular}

Berdasarkan Tabel 3 terlihat bahwa nilai $\chi_{\text {hitung }}^{2}$ kelas eksperimen maupun kelas kontrol lebih kecil dari pada nilai $\chi_{\text {tabel }}^{2}$. Hasil ini menunjukkan bahwa data postest kelas eksperimen maupun kelas kontrol terdistribusi normal.
3. Hasil Uji Homogenitas Posttest

Uji homogenitas pada penelitian ini menggunakan uji statistik $F$ dengan taraf signifikan $=0,05$. Uji Homogenitas dilakukan untuk melihat apakah data berasal dari varians yang sama atau tidak.

TABEL 4 HASIL UJI HOMOGENITAS POSTTEST KELAS EKSPERIMEN DAN KELAS KONTROL

\begin{tabular}{cccccc}
\hline No. & Kelas & Nilai Varians & Varians Hitung & $\begin{array}{c}\text { Nilai F tabel } \\
(a=0,05)\end{array}$ & Keputusan \\
\hline 1 & $\begin{array}{c}\text { Kelas XI MIPA 4 } \\
\text { (Eksperimen) }\end{array}$ & 10,08 & & 2,96 & $\begin{array}{c}\text { Kedua data } \\
\text { homogen }\end{array}$ \\
\cline { 1 - 2 } 2 & $\begin{array}{c}\text { Kelas XI MIPA 3 } \\
\text { (Kontrol) }\end{array}$ & 9,02 & 1,12 & 2,02 & \\
\hline
\end{tabular}

Berdasarkan hasil uji homogenitas pada Tabel 4 dengan taraf signifikan $(a=0,05)$, dari data tersebut terlihat bahwa $\mathrm{F}_{\text {hitung }}$ lebih kecil dari $\mathrm{F}_{\text {tabel }}$, maka berdasarkan kriteria pengambilan keputusan dapat disimpulkan bahwa tidak terdapat perbedaan varians antara kelas eksperimen dan kelas kontrol atau dengan kata lain varians antara kelas eksperimen dan kelas kontrol adalah sama atau homogen.

4. Uji Hipotesis (Uji-t)

Setelah terpenuhi uji normalitas dan homogenitas, maka dilakukan uji-t. Uji ini digunakan untuk memastikan apakah hipotesis yang dilakukan dapat diterima atau tidak. Uji $t$ tersebut diperoleh berdasarkan tes akhir (posttest).

TABEL 5 UJI BEDA RATA-RATA POSTTEST KELAS EKSPERIMEN DAN KELAS KONTROL

\begin{tabular}{|c|c|c|c|c|c|}
\hline No & Kelas & $\begin{array}{l}\text { Nilai rata-rata } \\
\bar{X}_{X}\end{array}$ & $t_{\text {hitung }}$ & $\begin{array}{c}t_{\text {tabel }} \\
(a=0,05)\end{array}$ & Keputusan \\
\hline 1 & Kelas Eksp. & 14,81 & \multirow{2}{*}{6,25} & \multirow{2}{*}{2,66} & \multirow{2}{*}{$\mathrm{H}_{0}$ diterima } \\
\hline 2 & Kelas Kontrol & 9,03 & & & \\
\hline $\begin{array}{l}\text { Sete } \\
\text { mengg } \\
6,25> \\
\text { berada } \\
\text { demikia }\end{array}$ & $\begin{array}{l}\text { akukan pengol } \\
\text { uji-t diperoleh } \\
\text { Hal ini menun } \\
\text { daerah pener } \\
\text { erima dan } \mathrm{H}_{0} \text { di }\end{array}$ & $\begin{array}{l}\text { data, dengan } \\
\text { hitung }>\text { ttabel atau } \\
\text { an bahwa thitung } \\
\text { n } H_{0} \text {. Dengan }\end{array}$ & \multicolumn{3}{|c|}{$\begin{array}{l}\text { pembelajaran kooperatif tipe talking stick disertai } \\
\text { metode eksperimen yang digunakan pada kelas } \\
\text { eksperimen ternyata memberikan hasil lebih baik } \\
\text { terhadap hasil belajar Fisika dibandingkan dengan } \\
\text { pemberian model pembelajaran direct instruction } \\
\text { (DI) pada kelas kontrol. }\end{array}$} \\
\hline $\begin{array}{r}\text { Pemba } \\
\text { Per } \\
\text { terdapa }\end{array}$ & $\begin{array}{l}\text { ini bertujuan ur } \\
\text { igaruh dari }\end{array}$ & $\begin{array}{l}\text { melihat apakah } \\
\text { berian model }\end{array}$ & \multicolumn{3}{|c|}{$\begin{array}{l}\text { Berdasarkan hasil pengujian hipotesis pada } \\
\text { post-test dengan menggunakan rata-rata skor } \\
\text { diperoleh } \mathrm{t}_{\text {hitung }}=6,255 \text { dan } \mathrm{t}_{\text {tabel }}=2,00247 \text {, maka }\end{array}$} \\
\hline
\end{tabular}


kriteria penerimaan Ho dimana $-\mathrm{t}(1-0,5 \alpha)<\mathrm{t}<\mathrm{t}(1-$ $0,5 \alpha)$ tidak terpenuhi, Ho ditolak dan $\mathrm{H}_{1}$ diterima dengan taraf nyata $\alpha=0,05$ dan $\mathrm{dk}(29+30-2)=$ 57 , artinya terdapat perbedaan hasil belajar Fisika antara kelas eksperimen dan kelas kontrol. Hal ini menunjukan bahwa ada pengaruh model pembelajaran kooperatif tipe talking stick terhadap hasil belajar Fisika.

Pada kelas eksperimen, setelah guru menyampaikan tujuan dan memotivasi peserta didik, peserta didik menyimak informasi berupa prosedur kerja pembelajaran kooperatif tipe Talking Stick dan materi pembelajaran. Kemudian peserta didik membentuk kelompok kooperatif yang beranggotakan 5-6 orang secara heterogen. Siswa melakukan percobaan yang dinstruksikan di LKPD. Siswa bekerjasama dan berdiskusi dalam menyelesaikan masalah yang tersedia dalam LKPD. Masing-masing kelompok mempresentasikan hasil diskusi di depan peserta didik lainnya. Setelah selesai melakukan presentasi peserta didik diberikan waktu untuk mempelajari kembali materi yang telah di ajarkan, kemudian guru mempersilahkan peserta didik untuk menutup bukunya. Guru mengambil tongkat dan memberikan kepada salah satu peserta didik kemudian guru memberikan pertanyaan kepada peserta didik yang memegang tongkat dan wajib menjawabnya, demikian seterusnya sampai seluruh kelompok mendapat gilirannya. Tongkat berpindah dari kelompok yang satu ke kelompok yang lainnya. Peserta didik yang mendapatkan tongkat wajib menjawab pertanyaan yang sudah di sediakan oleh guru. Jika peserta didik tidak dapat menjawab maka tongkat akan diberikan kepada peserta didik kelompok lain. Setelah semua kelompok mendapatkan gilirannya, peserta didik di berikan evaluasi untuk mengetahui tingkat pemahaman peserta didik terhadap materi yang diajarkan. Pada saat tongkat digilir, siswa nampak gugup karena takut mendapat giliran untuk menjawab. Oleh karena itu, peserta didik lebih mempersiapkan diri untuk mengikuti pembelajaran berikutnya untuk meminimalisir kegugupan mereka atas ketidakmampuan dalam menjawab soal.

Setelah diberi perlakuan, menguji kemampuan akhir peserta didik dengan memberikan posttest diketahui skor rata-rata untuk kelas eksperimen sebesar 14.81 dan untuk kelas kontrol 9,03. Dengan nilai rata-rata untuk kelas eksperimen sebesar 74,13 dan nilai rata-rata kelas kontrol 46,5 Hasil ini menunjukkan adanya perbedaan skor antara dua kelas, dimana skor rata-tara kelas eksperimen lebih tinggi dibandingkan kelas kontrol.

Berdasarkan uraian diatas telah dijelaskan bahwa hasil belajar kelas eksperimen lebih meningkat dari kelas kontrol. Hal ini di mungkinkan karena proses pembelajaran yang menggunakan model pembelajaran kooperatif tipe talking stick menjadikan peserta didik lebih aktif dan terlibat langsung dalam proses pembelajaran dikelas baik secara mandiri maupun secara berkelompok, saling berinteraksi dengan guru maupun dengan teman kelompoknya. Dengan model pembelajaran kooperatif ini selain membuat peserta didik lebih aktif, peserta didik juga dapat bermain sambil belajar dengan membuka wawasan mereka akan pelajaran yang telah dipelajarinya. Hal ini menunjukkan bahwa aktivitas peserta didik selama proses pembelajaran ketika guru mengajar dengan menerapkan model pembelajaran kooperatif tipe talking stick peserta didik lebih bersemangat dalam belajar.

Hasil penelitian ini sama dengan hasil penelitian yang dilakukan oleh ref. Fidmatan[6], Gintoe[7], dan Siregar[8] yang menyatakan bahwa dengan menerapkan model pembelajaran kooperatif tipe Talking Stick dapat meningkatkan minat belajar biologi peserta didik.

\section{KESIMPULAN DAN SARAN}

\section{Kesimpulan}

Berdasarkan analisis data penelitian dapat disimpulkan bahwa ada pengaruh model pembelajaran kooperatif tipe Talking stick terhadap hasil belajar fisika peserta didik pada materi suhu dan kalor di SMA Negeri 5 Palu. Pada hasil posttest, nilai rata-rata kelas eksperimen menggunakan model kooperatif tipe Talking stick lebih tinggi dibandingkan kelas kontrol yang menggunakan model pembelajaran Direct Intraction ( DI) yaitu 14,81 dan 9,03. Selain itu, berdasarkan hasil analisis data statistik menggunakan Uji-t dua pihak diperoleh nilai $t_{\text {hitung }}>t_{\text {tabel }}$ atau 6,255 $>2,00247$ pada taraf signifikan $\alpha=0,05$ sehingga hipotesis dapat diterima

\section{Saran}

Berdasarkan hasil penelitian yang telah diperoleh selama melakukan proses pembelajaran, maka penulis menyarankan :

1) Kepada guru bidang studi fisika, agar dapat menerapkan model kooperatif tipe Talking stick pada materi-materi fisika untuk meningkatkan hasil belajar fisika.

2) Bagi sekolah, Menyediakan beragam sumber informasi (cetak maupun elektronik) yang dibutuhkan dalam meningkatkan hasil belajar serta agar model kooperatif tipe Talking stick ini dapat dijadikan alternatif pembelajaran di sekolah untuk mata pelajaran lainnya.

3) Bagi peneliti selanjutnya agar sebaiknya dapat memperhitungkan waktu di setiap fase pembelajaran agar lebih efesien, karena waktu menjadi kendala dalam proses pembelajaran. 


\section{DAFTAR PUSTAKA}

[1] N.Wahidin, "Penerapan Strategi React dalam Pembelajaran Kontekstual untuk Meningkatkan Hasil Belajar Fisika Siswa Kelas Viiic SMP Negeri 13 Palu". Skripsi, Program Studi Pendidikan Fisika. Jurusan P. MIPA FKIP Universitas Tadulako. Tiak diterbitkan, 2011.

[2] Noryana, "Meningkatkan Minat Belajar PKN Materi Hak Asasi Manusia MenggunakanModel Pembelajaran Talking Stick pada Siswa Kelas X.A SMA Negeri 11Banjarmasin." 3, (5). Hal 1-8, 2013.

[3] A. Shoimin, "66 Model Pembelajaran Inofatif dalam Kurikulum 2013". Yogyakarta : Ar-ruzz media, 2014.

[4] R. Dewi, "Pengaruh Penggunaan Model Pembelajaran Talking Stick Terhadap Peingkatan Hasil Belajar Siswa SMA Inshafuddin". Skripsi sarjana pada Universitas Islam Negeri ArRanirydarussalam-Banda Aceh. Tidak diterbitkan, 2017.
[5] M. Y. Kholifudin, "Pembelajaran Fisika dengan Inkuiri Terbimbing Melalui Metode Eksperimen dan Demonstrasi Ditinjau dari Gaya Belajar Siswa". 0853-0823, 2012.

[6] S. S. dkk Fidmatan, "Penerapan Model Pembelajaran Kooperatif Tipe Talkingstick untuk Meningkatkan Minat dan Hasil Belajar Biologi Siswa pada Materi Pencemaran Lingkungan Kelas Xa di Sma Yapis Manokwari" 5, (1). Hal 1-12, 2016.

[7] K. Y. Gintoe, "pengaruh model pembelajaran kooperatif tipe Talking Stick Terhadap hasil belajar Ipa Fisika Pada Siswa Kelas VII SMP Negeri 9 Palu." Skripsi, Program Studi Pendidikan Fisika. Jurusan P-MIPA FKIP Universitas Tadulako. Tidak diterbitkan. 2015

[8] S. Siregar, "Pengaruh Model Pembelajaran Talking Stick Terhadap Hasil Belajar dan Aktivitas Visual Siswa Pada Konsep Sistem Indra." 3 (02). Hal 100-106, 2015.

[9] Sudjana. "Metode Statistik". Bandung: CV. Tarsito, 2005.

[10] Sugiyono. "Metode Penelitian Pendidikan Pendekatan Kuantitatif, Kualitatif, dan R\&D". Bandung: Alfabeta, 2015. 